
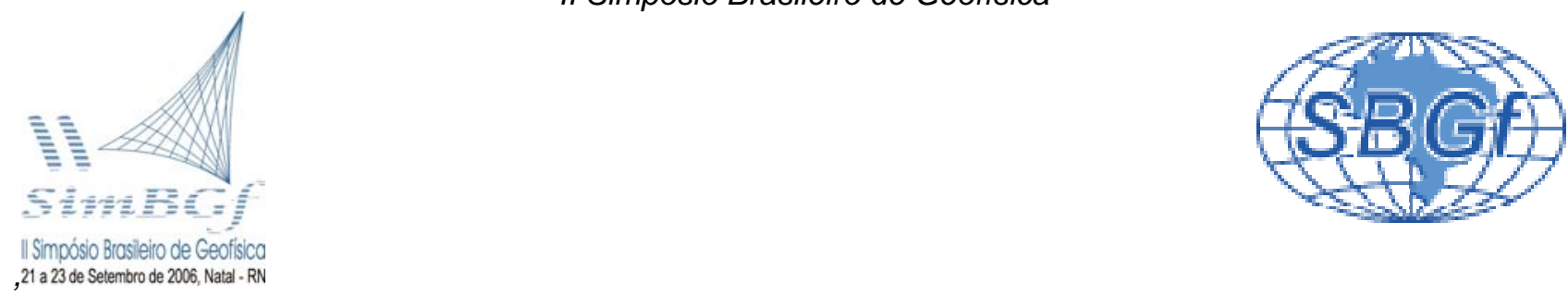

\title{
Geofísica Aplicada em área de Lançamento de Efluentes de Tratamento de Esgoto
}

\author{
César Augusto Moreira, João Carlos Dourado, Kátia dos Santos \\ UNESP - Campus de Rio Claro - SP
}

Copyright 2006, SBGf - Sociedade Brasileira de Geofísica

Este texto foi preparado para a apresentação no II Simpósio de Geofísica da Sociedade Brasileira de Geofísica, Natal, 21-23 de setembro de 2006. Seu conteúdo foi revisado pela Comissão Tecno-científica do I I SR-SBGf mas não necessariamente representa a opinião da SBGf ou de seus associados. E proibida a reprodução total ou parcial deste material para propósitos comerciais sem prévia autorização da SBGf.

\section{Resumo}

Este trabalho apresenta os resultados da aplicação do método geofísico de Eletrorresistividade, especificamente das técnicas de Sondagem Elétrica Vertical e Caminhamento Elétrico, no estudo de campo experimental, monitorado pela Escola Superior de Agronomia "Luis de Queiroz" - ESALQ, irrigado por efluentes gerados em lagoas de estabilização do tipo aeróbica-facultativa na ETE (Estação de Tratamento de Esgotos) Sabesp, no município de Lins-SP..

\section{Introdução}

Intervenções antrópicas no meio ambiente geram impactos negativos que, atualmente, constituem uma das grandes preocupações mundiais. A contaminação dos solos e águas subterrâneas pode se dar a partir de áreas de disposição de resíduos domiciliares, efluentes industriais e outros tipos de atividades antrópicas como, por exemplo, disposição de esgoto, atividades agrícolas e outras. Na avaliação destes tipos de contaminação, os conhecimentos adquiridos dos aspectos de natureza geológico-geotécnica e hidrogeológica da área e as características do material poluente devem ser levados em consideração para se determinar o comportamento dos contaminantes no meio físico e definição de medidas para proteção, conservação ou recuperação desse meio.

A Geofísica, cujas metodologias ao longo dos anos têm sido aperfeiçoadas e adaptadas em função da solicitação crescente nos mais variados campos de atuação, possui um papel de extrema importância em questões relacionadas à Geologia Ambiental, como ferramenta de estudo do meio físico na caracterização e monitoramento de contaminações de solos e águas subterrâneas. Entre os métodos geofísicos de prospecção, a eletrorresistividade é um dos mais usados no estudo da contaminação do meio ambiente, como se pode constatar pelo exposto por Elis (1998), Gallas (2000) e Moura (2002). Os diferentes tipos litológicos existentes apresentam como uma de suas propriedades fundamentais o parâmetro físico resistividade elétrica, o qual tem correspondência com algumas de suas características, servindo para caracterizar seus estados, em termos de alteração, fraturamento, saturação, etc., e até identificá-los quanto a litologia, sem necessidade de escavações (Braga, 2001)

Segundo pesquisa realizada pela Companhia de Saneamento do Paraná, Sanepar, em 1996, a disposição final na agricultura representa alternativa promissora para o problema de destinação final dos lodos e efluentes de ETEs, tanto pela adequação sanitária e ambiental como pela viabilidade econômica, desde que o resíduo atenda aos padrões mínimos de qualidade e sejam seguidos os critérios e cuidados preconizados pela Norma Técnica (SANEPAR, 1999; SANEPAR, 2000).

Neste trabalho, a eletrorresistividade é utilizada no reconhecimento de plumas de contaminação no "campo experimental para reuso de esgotos tratados", de propriedade da Sabesp, localizado próximo à zona urbana do município de Lins, SP.

\section{Área de estudos}

A área de estudos está localizada no município de Lins, Estado de São Paulo, distante $455 \mathrm{~km}$ à noroeste da capital (Figura 1):

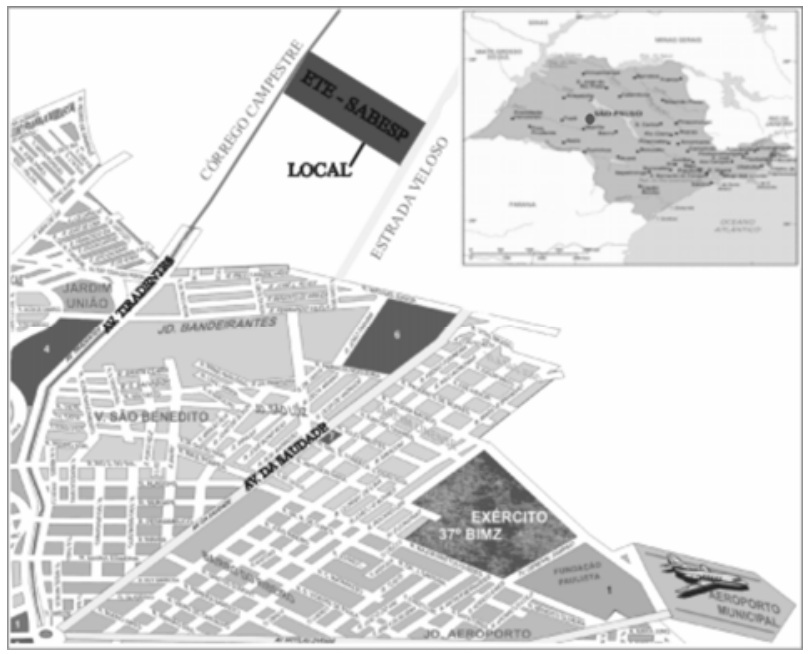

Figura 1 - Localização da área

À área consiste em um campo experimental para reuso de esgotos tratados, de propriedade da Sabesp, localizado próximo à zona urbana do município. Este campo é utilizado pela Escola Superior de Agricultura "Luiz de Queiroz" - ESALQ, no plantio experimental de café, cana-de-açúcar, milho, palmeira pupunha e capim 
tifton, cuja irrigação está sendo feita por efluentes de tratamento de esgoto residencial.

O município de Lins assenta-se sobre a Formação Adamantina (Coelho, 1999), pertencente ao Grupo Bauru, constituída por arenitos finos a muito finos, às vezes argilosos ou siltosos, constituídos por quartzo, pequena quantidade de feldspatos, sílica amorfa, opacos e mica. Apresentam boa seleção, arredondamento e esfericidade variáveis. Possuem cores avermelhadas e, às vezes, com tons amarelados.

A partir de ensaios de bombeamento em poços tubulares profundos, o DAEE determinou os parâmetros hidrodinâmicos para o aqüífero Adamantina na região de Lins. Os resultados obtidos foram: transmissividade entre 5 a $100 \mathrm{~m}^{3} / \mathrm{dia}$, permeabilidade aparente entre 0,01 a 1 $\mathrm{m} /$ dia e capacidade específica entre 0,1 a $2 \mathrm{~m} / \mathrm{h} /$ dia (DAAE, 1984). Na área de estudos, a profundidade do nível freático está em torno de $13 \mathrm{~m}$, com valores de condutividade hidráulica em torno $9,01 \times 10^{-2} \mathrm{~cm} / \mathrm{s}$.

\section{Materiais e Métodos}

O trabalho de campo foi realizado no mês de abril de 2005, com a aplicação das técnicas de Sondagem Elétrica Vertical em arranjo Schlumberger e Caminhamento Elétrico em arranjo Dipolo-dipolo. Foram executados cinco linhas de caminhamento com espaçamento de 20 metros entre os eletrodos e $200 \mathrm{~m}$ por linha, com sentido NE para SW. Foram efetuadas nove sondagens elétricas com abertura $A B / 2$ de 50 e 100 metros (Figura 2).

A partir da interpretação das sondagens elétricas, foi possível definir a profundidade do nível freático em diversos pontos, reunidos sob a forma de mapa potenciométrico, com sentido preferencial de fluxo d’água subterrânea (Figura 2).

\section{Resultados}

Analisando-se as curvas das SEVs, observa-se que é mantido um padrão no qual as primeiras camadas do substrato são mais resistivas e, conforme a profundidade aumenta, a resistividade diminui, não havendo nenhuma curva que saísse deste padrão. Este comportamento tem correspondência com as cinco seções de caminhamento elétrico realizadas.

A última camada se refere ao lençol freático. O modelo geoelétrico obedece aos seguintes padrões na distribuição das resistividades com a profundidade: $\rho_{1}<$ $\rho_{2}>\rho_{3}>\rho_{4}$ (SEV's 1, 3, 4, 5 e 6) e $\rho_{1}<\rho_{2}>\rho_{3}$ (SEV's 7, 8 e 9) (Figura 3). A SEV 2, situada a montante da área, foi o que apresentou a maior espessura de material resistivo superficial.

Quanto às linhas de caminhamento elétrico, após os dados de campo serem invertidos, foram obtidas seções geoelétricas. Nestes perfis é confirmado o padrão de resistividade descrito nas SEVs, no qual as primeiras camadas do substrato são mais resistivas e, conforme a profundidade aumenta, a resistividade diminui. As curvas das sondagens refletem as camadas superiores dos perfis do caminhamento, uma vez que para este foi utilizado espaçamento de 20 metros entre eletrodos, com conseqüente alcance de maior profundidade de investigação.

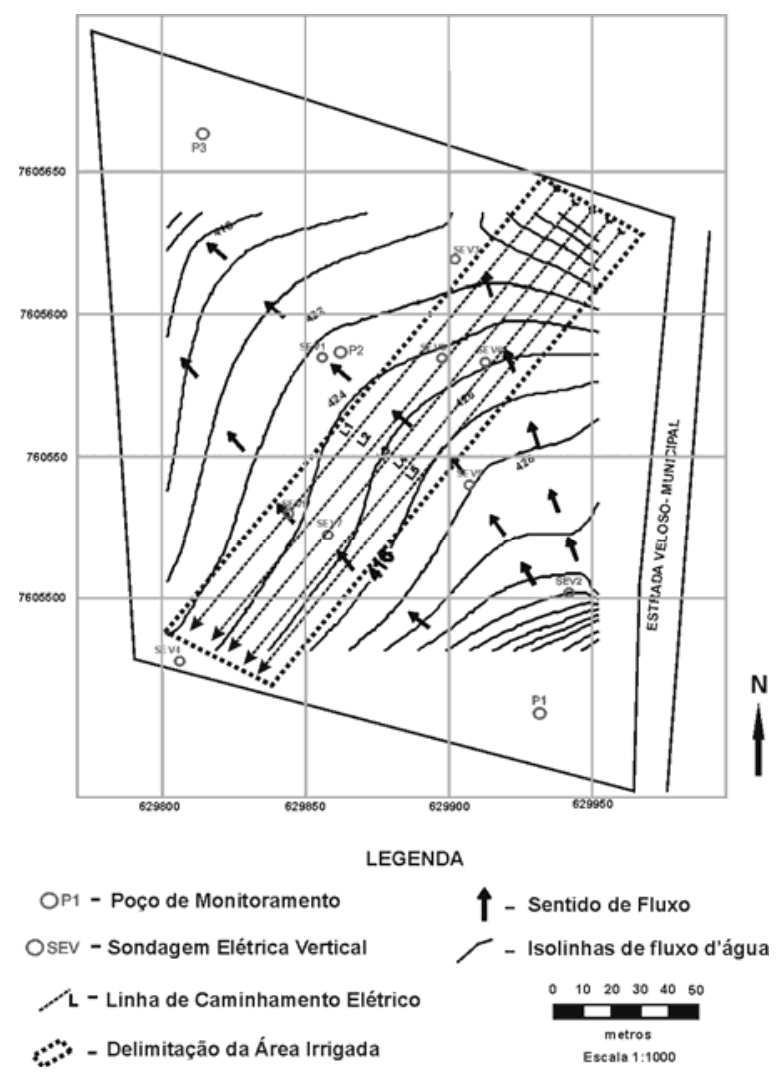

Figura 2 - Posição das linhas de Caminhamento Elétrico, pontos de Sondagem Elétrica Vertical e linhas de isovalores de profundidade do nível freático, com setas indicativas do sentido de fluxo d'água subterrânea.

As seções de caminhamento elétrico indicam a presença de uma anomalia condutiva localizada na porção NE da área (Figuras 5 a 9). Esta anomalia ocorre nas linhas do caminhamento elétrico nas seguintes posições: entre as posições 20 a 60m na L1 (Figura 5), entre as posições 0 a $20 \mathrm{~m}$ na L2 (Figura 6), entre as posições 0 e 60m na L3 (Figura 7), entre as posições 0 e 15m na L4 (Figura 8), e entre as posições 0 a 40m na L5 (Figura 9).

\section{Discussão e Conclusões}

As aplicações das técnicas de sondagem elétrica vertical e caminhamento elétrico se mostraram eficazes na determinação de uma anomalia de elevada condutividade (Figura 4). Esta anomalia coincide com um dos locais de injeção de efluentes da área de estudos, por meio da instalação de tanque do tipo "australiano" - sem fundo, com infiltração direta do efluente no solo a partir da pressão exercida pela coluna de líquido contida no tanque. 

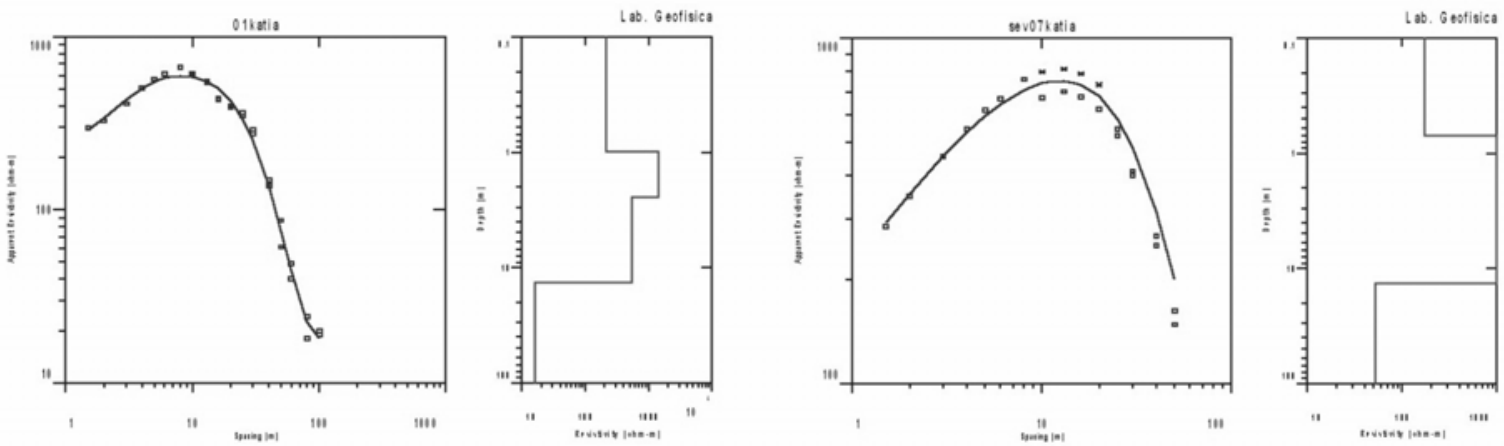

Figura 3 - Sondagens elétricas representativas da área de estudos. SEV 01 'esquerda e SEV 07 a direita.

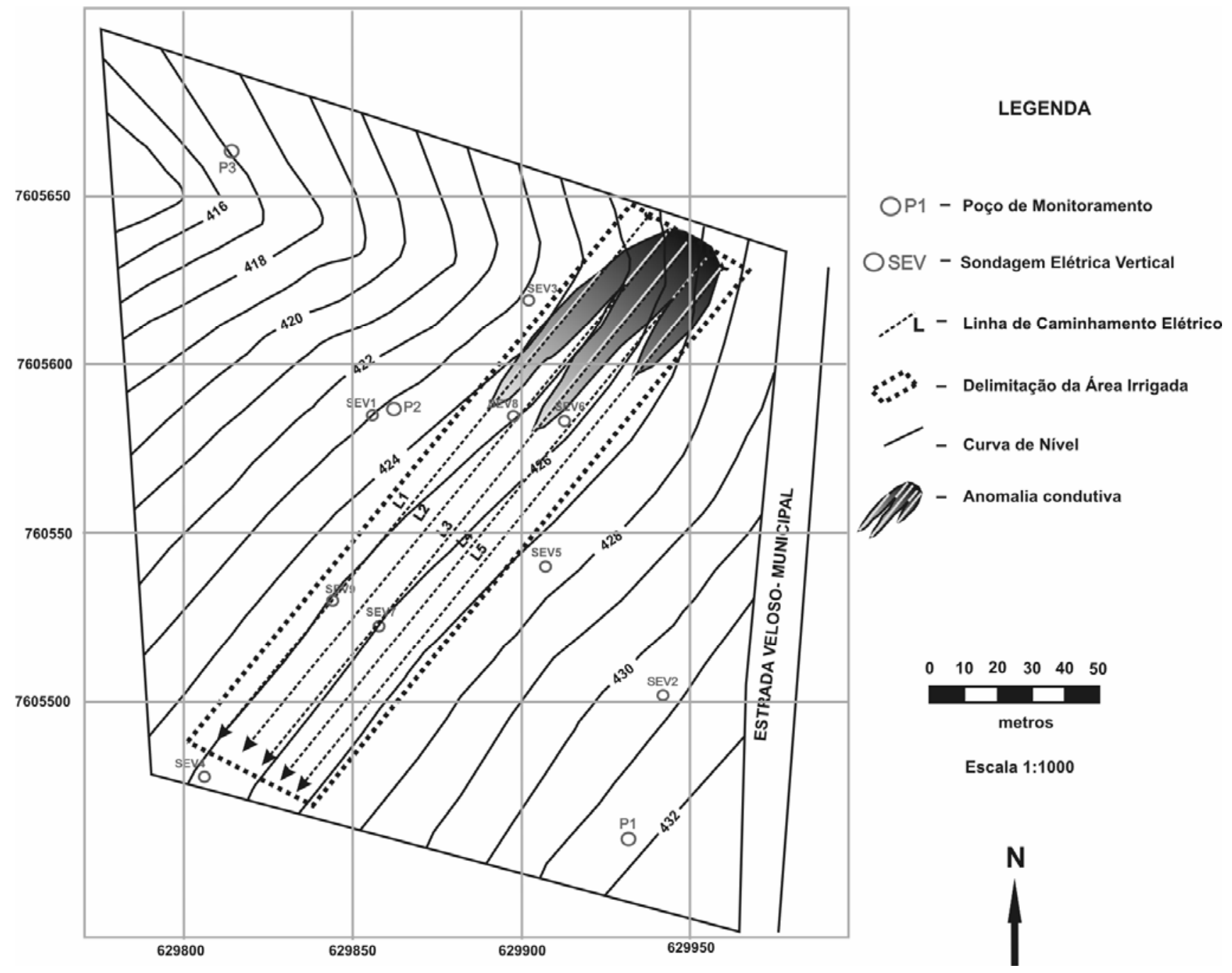

Figura 4 - Linhas de caminhamento elétrico com posição da anomalia de condutividade 
A caracterização da anomalia como de baixa condutividade está diretamente associada aos compostos presentes na efluente. A elevada quantidade de íons em solução, quando injetados em no ambiente geológico particularmente arenoso e resistivo, como neste caso, resultam no aumento da condutividade elétrica, com conseqüente caracterização por métodos geoelétricos e possivelmente, eletromagnéticos.

Os resultados demonstram a eficácia na percolação de efluentes no solo, aparentemente até o nível freático, conforme indicação principalmente nas linhas 1, 3 e 5 (Figuras 5, 7 e 9). Neste contexto, é preciso avaliar a possibilidade de contaminação das águas subterrâneas.

É possível definir o teor e tipos de elementos presentes no efluente a partir de análises químicas. A instalação de poços de monitoramento nos locais com conexão entre o efluente lançado em superfície e o nível freático, permitiriam avaliar o grau de retenção do solo e conseqüentemente, 0 teor residual de efluente que efetivamente atinge o nível freático. Desta forma, é possível avaliar o impacto do uso de efluentes gerados a partir de tratamento de esgoto nas águas subterrâneas.

O efluente pode eventualmente ser diluído em água limpa para redução de teores, com base na capacidade de retenção destes elementos em solo. O balanceamento desta solução permite a fertilização do solo em quantidades efetivamente utilizáveis, concomitante à redução nos riscos de contaminação das águas subterrâneas.

Este procedimento deve também considerar a demanda química da espécie cultivada, eventualmente variável, para que o balanceamento da solução supra as necessidades da cultura utilizada e seja minimamente impactante ao meio.

A técnicas geofísicas aplicadas neste trabalho podem contribuir no estabelecimento deste procedimento, por meio da determinação da profundidade do nível freático ao longo do ano e monitoramento da percolação de efluente.

\section{Agradecimentos}

Os autores agradecem ao técnico Francisco Garcia Barrera (Paco) e ao aluno Rodrigo Zanão pelo apoio aos trabalhos de campo.

\section{Referências}

Braga, A. C. O. Métodos Geoelétricos Aplicados. Apostila do curso de Geologia, Instituto de Geociências e Ciências Exatas - UNESP, Rio Claro (SP), 1999.

Coelho, T. A. F., 1999. Diagnóstico Geo-Ambiental da cidade de Lins - S.P. - Dissertação de Doutorado, IGCE Instituto de Geociências e Ciências Exatas, Unesp Campus de Rio Claro.
COMPANHIA DE SANEAMENTO DO PARANÁ SANEPAR. Revista Técnica da Sanepar. Curitiba, PR. V.12, nº 12 - Julho a Dezembro de 1999.

COMPANHIA DE SANEAMENTO DO PARANÁ SANEPAR. Revista Técnica da Sanepar. Curitiba, PR. V.13, n 13 - Janeiro a Junho de 2000.

DEPARTAMENTO DE ÁGUAS E ENERGIA ELÉTRICA. Caracterização dos recursos hídricos no Estado de São Paulo. São Paulo, DAEE, 1984.

Elis, V. R., 1998. Avaliação da Aplicabilidade de Métodos Elétricos de Prospecção Geofísica no Estudo de Áreas Utilizadas para Disposição de Resíduos. Tese de Doutorado, Instituto de Geociências Ciências Exatas, UNESP, Campus de Rio Claro - SP, 264p.

Gallas, J. D. F., 2000. Principais Métodos Geoelétricos e suas Aplicações em Prospecção Mineral, Hidrogeologia, Geologia de Engenharia e Geologia Ambiental Dissertação de Doutorado, IGCE - Instituto de Geociências e Ciências Exatas, Unesp - Campus de Rio Claro.

Moura H. P., 2002. Emprego da Eletrorresistividade e da Polarização Induzida na Caracterização Geoelétrica de Áreas de Disposição de Resíduos Sólidos Urbanos Dissertação de Doutorado, IGCE - Instituto de Geociências e Ciências Exatas, Unesp - Campus de Rio Claro. 


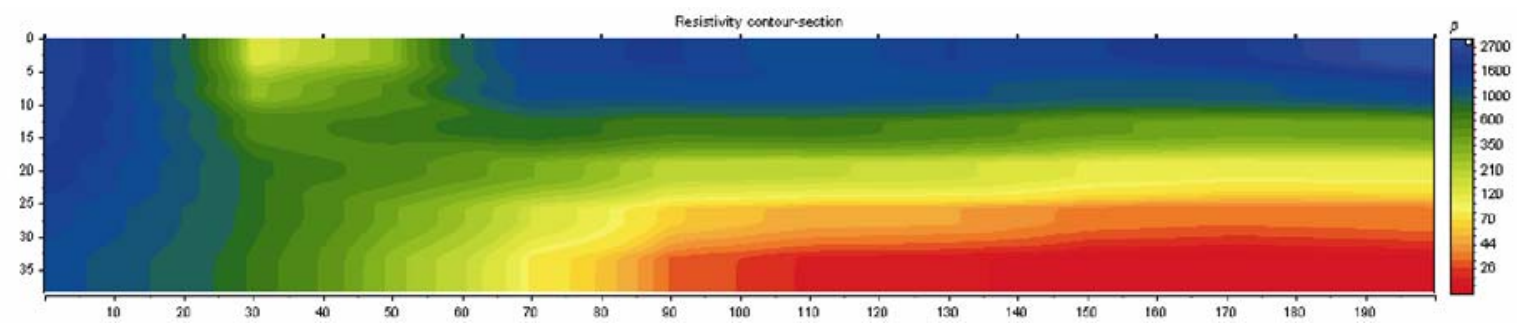

Figura 5 - Seção de Caminhamento Elétrico da Linha 1

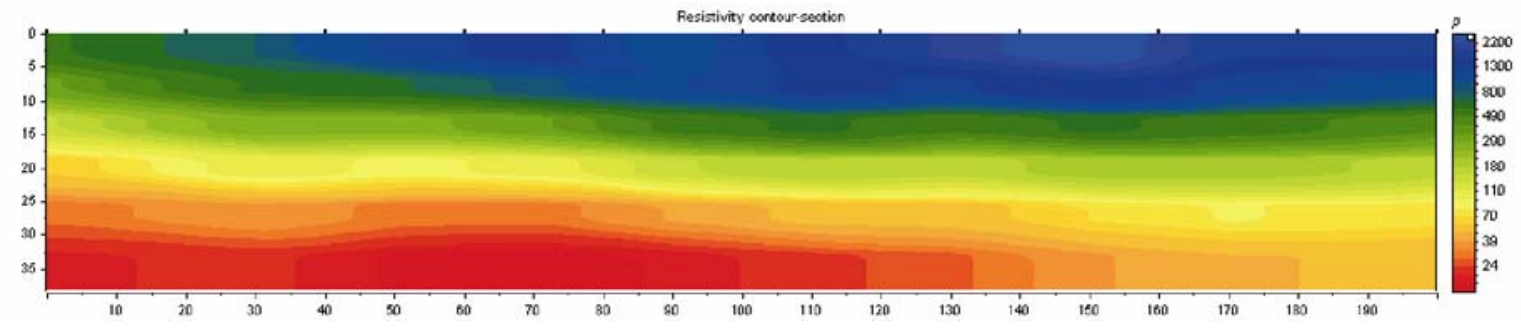

Figura 6 - Seção de Caminhamento Elétrico da Linha 2

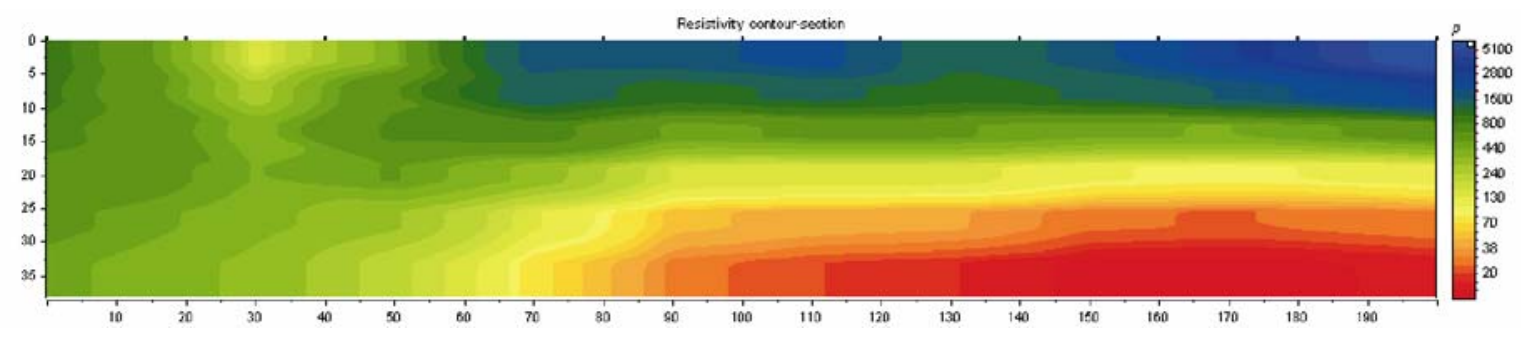

Figura 7 - Seção de Caminhamento Elétrico da Linha 3

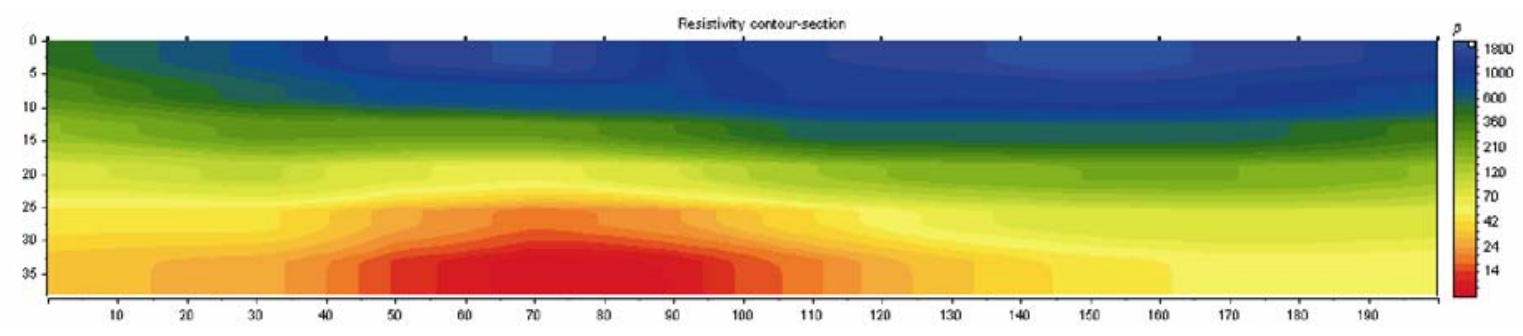

Figura 8 - Seção de Caminhamento Elétrico da Linha 4

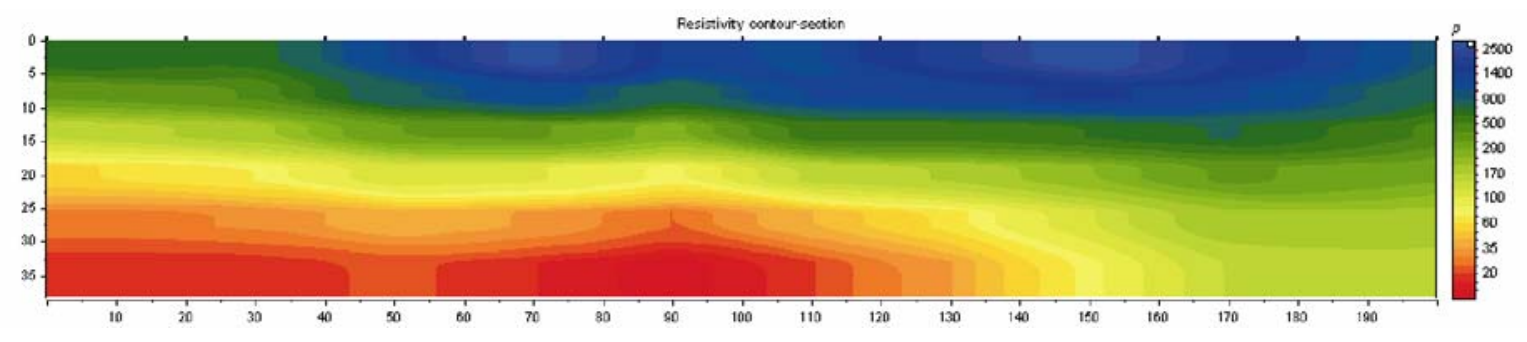

Figura 9 - Seção de Caminhamento Elétrico da Linha 5 
Geofísica aplicada em área de Lançamento de Efluentes

II Simpósio Brasileiro da SBGf, Natal 21-23 de setembro de 2006 